\title{
Is cytisine contraindicated in smoking patients with coronary artery disease after percutaneous coronary intervention?
}

\author{
Bogumił Ramotowski, Andrzej Budaj \\ Department of Cardiology, Centre of Postgraduate Medical Education, Warszawa, Poland
}

\author{
Correspondence to: \\ Bogumił Ramotowski, MD, \\ PhD, \\ Department of Cardiology, \\ Centre of Postgraduate \\ Medical Education, \\ Grochowski Hospital, \\ Grenadierów 51/59, \\ 04-073 Warszawa, Poland \\ phone: +48225152660 \\ e-mail: bramotowski@cmkp. \\ edu.pl \\ Copyright by the \\ Author(s), 2021 \\ Kardiol Pol. 2021. \\ 79 (7-8): 813-819. \\ DOl: 10.33963/KP.a2021.0025 \\ Received: \\ March 25, 2021 \\ Revision accepted: \\ March 30, 2021 \\ Published online: \\ May 31, 2021
}

\author{
A B S TR A C T \\ Background: Cytisine is contraindicated, and its effects have not been evaluated in patients with \\ coronary artery disease (CAD).
}

Aims: The safety, feasibility, and short-term efficacy of cytisine for smoking cessation were evaluated in active smokers with CAD after percutaneous coronary interventions (PCI).

Methods: Patients with stable CAD and acute coronary syndromes (ACS), who smoked at least 10 cigarettes per day, were included 30 days post $\mathrm{PCl}$ and offered cytisine therapy. Adverse events, smoking activity, and drug adherence were assessed after 30 days.

Results: 117 patients participated (mean standard deviation [SD] age, 60.8 [7.7] years; men, 73.6\%, median and interquartile range [IQR] of the number of pack-years, 40 [30-46.5]). Overall, 79 patients consented (study group) and 38 declined (control group) to use cytisine. At the follow-up visit, the incidence of adverse events did not differ between groups ( $17.7 \%$ vs $21 \% ; P=0.67)$. The groups had a similar success rate of smoking cessation in the intention-to-treat analysis ( $41.8 \%$ vs $36.8 \% ; P=0.61$ ). In the as-treated analysis, patients who completed the therapy achieved a higher success rate than those who declined $(69.7 \%$ vs $36.9 \% ; P=0.006)$ or did not complete therapy $(69.7 \%$ vs $34.8 \% ; P=0.01)$. In the multivariable analysis, complete cytisine therapy and ACS at admission were associated with an increased and male sex with a decreased chance of smoking cessation.

Conclusions: Cytisine therapy is not associated with an increase in adverse events in patients with CAD after $\mathrm{PCl}$. Cytisine is tolerable but effective in short-term follow-up only when the treatment is completed.

Key words: coronary artery disease, cytisine, acute coronary syndrome, percutaneous coronary intervention, smoking cessation

Kardiol Pol 2021; 79, 7-8: 813-819

\section{INTRODUCTION}

Cardiovascular diseases are the most common cause of death among cigarette smokers [1]. Thus, smoking cessation, an effective lifestyle intervention [2], is crucial for primary and secondary prevention of coronary artery disease (CAD). Pharmacotherapy for smoking cessation significantly increases the rate of smoking cessation, but it is rarely implemented in clinical settings $[3,4]$. First-line pharmacotherapies with nicotine replacement therapy (NRT), varenicline or bupropion, are the recommended course of action for smoking cessation [5]. NRTs (gum, transdermal patch, nasal spray, inhaler, and sublingual tablets/lozenges) increase the probability of smoking cessation, with a risk ratio of 1.6, compared with placebo [6]. The hemodynamic effects of NRT, due to nicotine release, cause adverse effects such as hypertension; thereby, NRT is less preferred among patients with CAD. Varenicline, a partial agonist of the a4-ß2 nicotinic acetylcholine receptor ( $\mathrm{nAChR}$ ), increases two-fold the success rate of effective smoking cessation [7]. Moreover, patients with acute coronary syndromes (ACS) treated with varenicline show a $10 \%$ increase in smoking abstinence compared with placebo, without an increase in major adverse cardiovascular events [8]. Another partial agonist of the a4- $32 \mathrm{nAChR}$, with a similar mechanism of action as varenicline, is cytisine, which is naturally derived from Cytisus laburnum and affects the reward pathway [9, 10]. The treatment duration with cytisine ( 25 days) is substantially shorter than with varenicline (12 weeks) which may influence the lack of non-inferiority of cytisine vs varenicline in recent trial [11]. Nevertheless, cytisine is inexpensive 
WHAT'S NEW?

Cytisine increases the success rates of smoking cessation in the general population. Due to lack of relevant data the drug was contraindicated in patients early after acute coronary syndromes (ACS) or unstable coronary artery disease, with special alert to patients with coronary artery disease (CAD). This is the first prospective study to assess the safety and short-term effectiveness of cytisine on smoking cessation in active smokers with $C A D$, who have undergone percutaneous coronary intervention ( $P C I$ ). Our findings suggest that cytisine may be introduced in a wider group of patients with CAD.

and outperforms NRTs (odds ratio [OR] 1.5; 95\% confidence interval $[\mathrm{Cl}] 1.2-1.9 ; P=0.003$ ) for smoking cessation $[7,12]$. Despite large randomized trials, cytisine is registered only in Europe and still not approved in the United States. Due to low cost and high accessibility, cytisine might be an option as a smoking cessation aid in secondary prevention in patients with CAD. However, to the best of our knowledge, there have been no published studies regarding cytisine use in patients with CAD after percutaneous coronary intervention $(\mathrm{PCl})$. Cytisine was registered for the approved indications, except for early ACS or unstable coronary disease, with a special alert to patients with $C A D$, owing to the lack of relevant data at the time of approval [13]. Furthermore, the registration was based on unpublished data from the 1960s; the data did not include patients who underwent $\mathrm{PCl}$. This data has not been updated since then, despite substantial progress in the interventional treatment of CAD. Furthermore, contraindications to cytisine in these groups of patients are not well documented and are based on a mild elevation in blood pressure, transient tachycardia, and blood glucose levels [9, 14-16]. These effects are driven by adrenergic stimulation and by neuronal and adrenal $n A C h R$ activation. Both cytisine and nicotine have a high affinity to the $\alpha 4-\beta 2$ subtype, which is involved in the mechanism of action of nicotine $[9,14]$.

In the present study, we sought to evaluate the safety, feasibility, and efficacy of cytisine use for smoking cessation in active smokers with CAD within 30 days post $\mathrm{PCl}$. We hypothesized that cytisine use will increase the rate of successful smoking cessation without an increased rate of adverse events.

\section{METHODS}

\section{Study population}

This was a nonrandomized prospective investigation of active smokers, following $\mathrm{PCI}$. Patients with stable CAD and ACS admitted to the catheterization laboratory in the Department of Cardiology, Grochowski Hospital, Warsaw, Poland between 2015 and 2018 were screened for active smoking. The inclusion criteria for patients were as follows: 28-32 days after $\mathrm{PCl}$, aged 18 years or older, smoking at least 10 cigarettes a day, urine cotinine level of 6 based on the NicAlert test [17], and planning to quit smoking. The exclusion criteria were as follows: hypersensitivity to cytisine, clinically relevant heart rhythm disorder, uncon- trolled hypertension, class III CAD according to Canadian Cardiovascular Society, the use of other agents for smoking cessation and pregnancy. Medical history, nicotine dependence, and readiness for smoking cessation were determined at baseline. Patients were included based on the self-declaration to quit smoking; the readiness to quit smoking score was assessed. Adverse events, smoking activity based on the NicAlert test, and drug adherence were assessed at the follow-up visit 28-32 days after the baseline visit. Patients who did not attend the follow-up visit were contacted by telephone.

\section{Ethical considerations}

This study complied with the Declaration of Helsinki and was approved by the ethics committee of the Centre of Postgraduate Medical Education (approval number $16 / \mathrm{PB} / 2014$ and 10/PB-A/2015). The study was registered at ClinicalTrials.gov and the identifier NCT040784702 was assigned. All patients provided written informed consent for participation in the study. Patients were recruited in the Department of Cardiology of the Centre of Postgraduate Medical Education, Warsaw, Poland.

\section{Smoking status}

The Fagerström test and readiness to quit smoking score were used to assess nicotine dependence and motivation to quit smoking, respectively; these were performed at baseline. The Fagerström test is the most commonly used test to assess nicotine dependence. Levels 6 and above predict a high level of nicotine dependence and indicate the need for a high level of behavioral support and pharmacological aid $[18,19]$. The readiness to quit score, which assesses the motivation to quit smoking, consists of 12 questions, and it was locally developed for Polish patients. Levels 7 and above indicate a high motivation for smoking cessation [20]. Self-declaration of smoking status was verified by evaluating urine cotinine level at baseline and follow-up visits (30 days) using the Accutest NicAlert (Jant Pharmacal Corporation, Encino, CA, USA); a level of 0 , 1 , or 2 indicated a urine cotinine level of $\leq 100 \mathrm{ng} / \mathrm{ml}$ and confirmed smoking cessation [17].

\section{Interventions}

All patients declared to willingly attempt to quit smoking. All patients were advised to stop smoking and received low-intensity counseling focused on the benefits of 
quitting, such as the reduced risk of CAD. Additionally, behavioral therapy was offered, which consisted of brief medical advice, psychological advice ( $<30$ minutes), and being contacted twice during follow-up. Standard cytisine therapy (Desmoxan; $1.5 \mathrm{mg}$ tablet, a 25 -day course) was offered to all patients, and cytisine therapy was started at the discretion of the patients. The study group consisted of patients who consented to start cytisine therapy. Patients who denied cytisine therapy represented the control group.

\section{Endpoints}

The primary endpoint was the differences in adverse events between the study and the control group. The observed adverse events were as follows: gastrointestinal symptoms, including dry mouth, nausea, and abdominal pain; psychiatric symptoms, including anxiety, insomnia, and suicidal thoughts; cardiovascular symptoms, including chest pain, increased blood pressure (mean self-measured blood pressure $\geq 140 / 90 \mathrm{~mm} \mathrm{Hg}$, or single measurement $\geq 180 / 110 \mathrm{~mm} \mathrm{Hg}$ either self-measured or measured at clinical visit), and arrhythmia. Major adverse events observed were myocardial infarction, stroke, hospitalization, and death from any cause.

The secondary endpoint was confirmed smoking cessation using the NicAlert test at the follow-up visit.

\section{Statistical methods}

It was estimated to enroll 117 patients powered to have an $80 \%$ chance of detecting a between-group difference of $25 \%$ in smoking cessation using a $P$ value of 0.05 with a $10 \%$ drop-out rate. Baseline characteristics were presented as mean and SD or median and interquartile range (IQR) for continuous data normally and non-normally distributed, respectively, and frequency for categorical data. A Shapiro-Wilk test was applied to assess for data normality. A t-test or Wilcoxon rank-sum test was used for between-group comparisons of continuous data. The Chi-squared or the Fisher exact test was used for between-group comparisons of categorical data. A multivariable logistic regression model was used to investigate the covariates associated with higher odds of smoking cessation. The following variables were included in the model: age, sex, body mass index, education, marital status, number of pack-years of smoking, previous attempts to stop smoking, passive smoking, the Fagerström index, readiness to quit score, the reason for $\mathrm{PCI}$ (CAD or ACS), and medical history. Relevant medical histories included: myocardial infarction, stroke, coronary artery bypass grafting, $\mathrm{PCl}$, hypertension, hyperlipidemia, chronic obstructive pulmonary disease, peripheral artery disease, diabetes mellitus, renal failure, and rheumatoid arthritis. The backward selection at a level of 0.1 was implemented to fit the model to identify factors at the $5 \%$ level of significance. ORs with $95 \% \mathrm{Cl}$ were calculated. All analyses were performed using the Stata 14.1 software (StataCorp LP, College Station, Texas, USA).

\section{RESULTS}

One hundred and seventeen active smokers with a level of 6 (NicAlert) were included in this study, 28-32 days post-PCI. Seventy-nine (67.5\%) patients consented to use cytisine (study group) at the first visit (baseline) (Figure 1). The remaining 38 (32.5\%) patients declined cytisine treatment (control group). Among patients who declined to use cytisine 6 (15.8\%) declared strong will to withdraw from smoking which according to the patient did not require pharmaceutical help, 4 (10.5\%) clearly declared that they would not use cytisine due to cardiovascular contraindications mentioned in the product information, $28(73.7 \%)$ refused but did not provide a particular reason. Of the patients who consented to use cytisine at the first visit, only 64 started cytisine treatment; 15 patients did not start the treatment despite consenting. Of the 64 patients who started cytisine treatment, 32 completed the 25-day course. Ninety-one patients ( 64 from the study group and 27 from the control group) completed the 30-day follow-up visit. Of these, 47 patients quit smoking; confirmed using the NicAlert test (levels from 0-2), and 44 patients did not quit smoking (levels $\geq 3$ ). All patients from the study group who attended the follow-up visit had started cytisine therapy. Patients who did not attend the follow-up visit were contacted via telephone and requested to complete a questionnaire regarding smoking cessation, cytisine use, and adverse events. All patients who failed to attend the follow-up visit did not stop smoking and declared lack of motivation as the reason for not attending the follow-up visit.

The clinical characteristics of the patients enrolled in the trial are presented in Table 1. The mean (SD) age of patients was 60.8 (7.7) years; $67(73.6 \%)$ patients were men, and 42 (46.15\%) patients underwent PCI for ACS. The median and interquartile range (IQR) of the number of cigarettes smoked was 14.5 (10-20), and the pack-years was 40 (30-46.5). The mean of Fagerström and readiness to quit index indices were $4.8 \pm 1.7$ and $9.0 \pm 1.6$, respectively.

The clinical characteristics of the patients in the study group did not differ from the control group (Table 1). Neither the criterion for high nicotine addiction (Fagerström index $\geq 6$ ) nor increased motivation for smoking cessation (readiness to quit score $\geq 7$ ) differed between the groups at baseline.

The frequency of all adverse events was similar between the groups (14 [17.7\%] vs 8 [21\%]; $P=0.67$ ). Additionally, the prevalence of particular adverse events did not differ between the groups (Table 2). Among all of the adverse events, the most common were gastrointestinal symptoms (10 [45\%]; nausea, 5 [23\%]; abdominal pain, 3 [14\%]; and dry mouth, 2 [9\%]). Other reported adverse events were increased anxiety, 5 (23\%); insomnia, 2 (9\%); atypical chest pain, 3 (14\%); and increased blood pressure, 2 (9\%). No major cardiovascular adverse events were reported at follow-up. Thirty-two patients (40.5\%) discontinued cytisine therapy. The most common reason for cytisine discontin- 


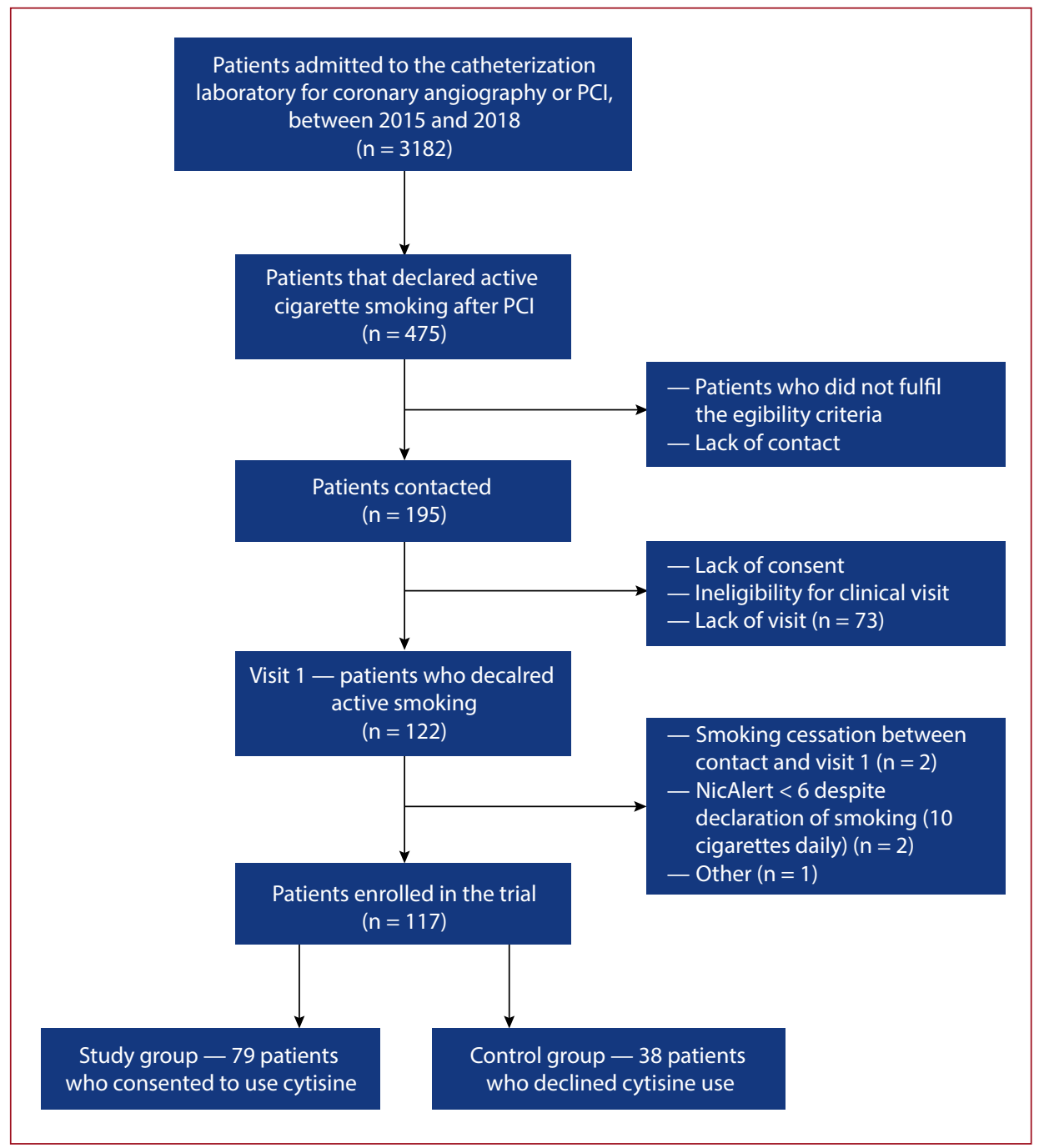

Figure 1. Flow chart of the study.

Abbreviations: $\mathrm{PCl}$, percutaneous coronary intervention

Table 1. Patient demographics and clinical characteristics

\begin{tabular}{|c|c|c|c|c|}
\hline Variables & $\begin{array}{l}\text { Baseline visit } \\
\quad(n=117)\end{array}$ & $\begin{array}{l}\text { Study group } \\
(\mathbf{n = 7 9 )}\end{array}$ & $\begin{array}{l}\text { Control group } \\
(n=38)\end{array}$ & $\begin{array}{c}\text { P-value } \\
\text { (study vs control group) }\end{array}$ \\
\hline $\begin{array}{l}\text { Age, years, mean (SD) } \\
\text { Range, years }\end{array}$ & $\begin{array}{c}60.8(7.7) \\
(56-65)\end{array}$ & $\begin{array}{l}59.9(7.8) \\
(58-62)\end{array}$ & $\begin{array}{c}59.8(7.8) \\
(57-62)\end{array}$ & 0.951 \\
\hline Males, $\mathrm{n}(\%)$ & $67(57.2)$ & $61(77.2)$ & $25(66)$ & 0.19 \\
\hline $\mathrm{BMI}, \mathrm{kg} / \mathrm{m}^{2}$, mean $(\mathrm{SD})$ & $27.9(4.4)$ & $28(4.2)$ & $28.1(4.9)$ & 0.91 \\
\hline Indications for PCI ACS, n (\%) & $55(47)$ & $33(41.8)$ & $22(57.9)$ & 0.102 \\
\hline Diabetes, n (\%) & $29(24.8)$ & $19(24)$ & $10(26.3)$ & 0.79 \\
\hline Hypertension, n (\%) & $94(80.3)$ & $63(79.75)$ & $30(78.95)$ & 0.92 \\
\hline History of Ml, n (\%) & $30(25.6)$ & $20(25.3)$ & $10(26.3)$ & 0.908 \\
\hline Hyperlipidemia, n (\%) & $84(71.8)$ & $53(67)$ & $31(81.6)$ & 0.103 \\
\hline History of renal failure, $\mathrm{n}(\%)$ & $7(5.9)$ & $5(6.3)$ & $2(5.2)$ & 1.0 \\
\hline COPD, n (\%) & $8(6.8)$ & $6(7.6)$ & $2(5.2)$ & 1.0 \\
\hline Data on smoking number of cigarettes smoked, median (IQR) & $14.5(10-20)$ & $12(10-20)$ & $15(10-20)$ & 0.54 \\
\hline Habit of smoking, years, median (IQR) & $40(32.5-45)$ & $40(33-45)$ & $40(30-43)$ & 0.32 \\
\hline Pack-years, median (IQR) & $40(30-46.5)$ & $40(30-47)$ & $39(27-36)$ & 0.46 \\
\hline $\begin{array}{l}\text { Fagerström questionnaire, mean (SD) } \\
\text { Index } \geq 6 ; \mathrm{n}(\%)\end{array}$ & $4.8(1.7)$ & $\begin{array}{l}4.8(1.8) \\
34(43)\end{array}$ & $\begin{array}{l}4.9(1.6) \\
15(39.5)\end{array}$ & $\begin{array}{l}0.607 \\
0.714\end{array}$ \\
\hline $\begin{array}{l}\text { Readiness to quit test, mean (SD) } \\
\text { Index } \geq 7 ; \mathrm{n}(\%)\end{array}$ & $9(1.6)$ & $\begin{array}{l}9.1(1.5) \\
76(96.2)\end{array}$ & $\begin{array}{l}8.8(1.7) \\
35(92)\end{array}$ & $\begin{array}{l}0.377 \\
0.347\end{array}$ \\
\hline
\end{tabular}

Abbreviations: $\mathrm{ACS}$, acute coronary syndrome; $\mathrm{BMI}$, body mass index; COPD, chronic obstructive pulmonary disease; IQR, interquartile range; $\mathrm{Ml}$, myocardial infarction; $\mathrm{PCI}$, percutaneous coronary intervention; SD, standard deviation 
Table 2. Frequency of adverse events

\begin{tabular}{l|c|c|c}
\multicolumn{1}{c|}{ Adverse events } & $\begin{array}{c}\text { Study } \\
\text { group }\end{array}$ & $\begin{array}{c}\text { Control } \\
\text { group }\end{array}$ & P-value \\
\hline Nausea, $\mathrm{n}(\%)$ & $4(5)$ & $1(2.6)$ & 1.0 \\
Abdominal pain, $\mathrm{n}(\%)$ & $1(1.3)$ & $0(0)$ & 1.0 \\
Dry mouth, $\mathrm{n}(\%)$ & $2(2.5)$ & $0(0)$ & 1.0 \\
Anxiety, $\mathrm{n}(\%)$ & $2(2.5)$ & $3(7.9)$ & 0.327 \\
Insomnia, $\mathrm{n}(\%)$ & $2(2.5)$ & $0(0)$ & 1.0 \\
Atypical chest pain, $\mathrm{n}(\%)$ & $3(3.8)$ & $2(5.3)$ & 0.639 \\
Increase in blood pressure, $\mathrm{n}(\%)$ & $1(1.3)$ & $1(2.6)$ & 0.546 \\
\hline
\end{tabular}

uation was a perceived lack of effectiveness (19 [59.3\%]). Thirteen patients $(20.3 \%)$ who started cytisine therapy discontinued treatment due to adverse events.

The study and control groups had similar success rates of smoking cessation in an intention-to-treat analysis (33 [41.8\%] vs 14 [36.8\%]; $P=0.61$ ). An analysis of patients who completed cytisine therapy revealed that only the patients who completed cytisine therapy significantly succeeded in smoking cessation compared with those not treated with cytisine, or those who did not complete cytisine therapy (Table 3) (complete therapy: 69.7\%; not treated: $36.8 \%$; incomplete therapy, $25 \% ; P<0.001$ ). According to the multivariable logistic regression analysis, completion of cytisine therapy (OR: $5.79 ; 95 \% \mathrm{Cl}: 1.99-16.86)$ and ACS at admission (OR: 3.2; 95\% Cl: 1.05-9.78) were associated with an increased success rate of smoking cessation, whereas decreased smoking cessation was observed with male sex (OR: 0.21; 95\% Cl: 0.06-0.68) (Table 4).

\section{DISCUSSION}

To the best of our knowledge, this is the first prospective study to assess the safety and effect of cytisine on smoking cessation in active smokers with CAD previously treated

Table 3. Success rates in smoking cessation concerning complete cytisine therapy

\begin{tabular}{l|c|c|}
\multicolumn{1}{c|}{ Groups } & Frequency & P-value \\
\hline $\begin{array}{l}\text { Complete cytisine therapy vs } \\
\text { incomplete therapy, n (\%) }\end{array}$ & $23(69.7)$ vs $24(34.8)$ & 0.001 \\
$\begin{array}{l}\text { Complete cytisine therapy vs } \\
\text { no therapy, n (\%) }\end{array}$ & $23(69.7)$ vs $14(36.8)$ & 0.006 \\
$\begin{array}{l}\text { Incomplete cytisine therapy vs } \\
\text { no therapy, n (\%) }\end{array}$ & $10(25)$ vs $14(36.8)$ & 0.257 \\
\hline
\end{tabular}

Table 4. Factors influencing the success in smoking cessation at follow-up visit - multivariable regression analysis

\begin{tabular}{l|c|c}
\multicolumn{1}{c|}{ Variables } & OR $(95 \%$ CI) & P-value \\
\hline $\begin{array}{l}\text { Complete cytisine therapy } \\
\text { (complete vs others) }\end{array}$ & $5.79(1.99-16.86)$ & 0.001 \\
$\begin{array}{l}\text { ACS at admission } \\
\text { (yes vs no) }\end{array}$ & $3.2(1.05-9.78)$ & 0.041 \\
$\begin{array}{l}\text { Male sex } \\
\text { (male vs female) }\end{array}$ & $0.21(0.06-0.68)$ & 0.01 \\
\hline
\end{tabular}

Abbreviations: ACS, acute coronary syndrome; $\mathrm{Cl}$, confidence interval; $\mathrm{OR}$, odds ratio with $\mathrm{PCl}$. Our results revealed that cytisine use in this group of patients was not associated with an increased risk of adverse events. However, a substantial proportion of patients did not start cytisine therapy despite obtaining the drug, and a substantial proportion of patients did not complete the therapy. Noteworthy, only a complete course of cytisine was associated with a higher rate of smoking cessation.

To our knowledge, there have been no previous reports on cytisine treatment in patients with CAD and the safety of this drug in the early period post- $\mathrm{PCl}$, especially in patients with ACS. A meta-analysis on NRT proved a higher incidence of symptoms related to sympathomimetic effects of nicotine such as tachycardia and arrhythmia, without an increase in major adverse cardiovascular events [21]. Cytisine is a partial nicotine agonist; therefore, it may cause similar symptoms $[9,14-16]$. In this trial, only a small number of patients reported atypical chest pain or elevated blood pressure, which might be attributable to nAChR activation; we did not observe any events of tachycardia or arrhythmia. In patients with stable CAD treated with varenicline, the rate of cardiovascular events was comparable to placebo [22]. Among these patients, the most commonly reported symptoms were nausea, vomiting, insomnia, and abnormal dreams [22]. The most common adverse events in our study were gastrointestinal symptoms such as nausea, and this is consistent with the findings of previous studies with cytisine [23]. We did not record any major adverse events such as serious cardiovascular events.

In our trial, patients were recruited 30 days after $\mathrm{PCl}$. Due to the lack of published data on cytisine use, a 30-day waiting period following $\mathrm{PCl}$ was chosen to avoid the period of the highest risk of cardiovascular adverse events and major fluctuations in platelet reactivity [24, 25].

In the largest randomized study on cytisine published to date, West et al. [26] reported a smoking cessation rate of $8.4 \%$ (vs $2.4 \%$ ) during 12 months of observation, and abstinence was verified by assessing the concentration of carbon monoxide. However, patients with a previous diagnosis of severe atherosclerotic disease and who had undergone $\mathrm{PCl}$ were excluded from the latter study. In our study, we found relatively high rates of smoking cessation (69.7\% in the complete cytisine therapy group, $36.8 \%$ in the no therapy group, and $25 \%$ in the incomplete therapy group). The high rate of cessation may be owing to the preselection of patients with established CAD treated with $\mathrm{PCl}$, short observation period, or the high level of counseling. On the other hand, the rate of cytisine discontinuation in our trial was $40.5 \%$, whereas the previously reported rate of varenicline discontinuation was 9.6\% [22]. The most common reason for discontinuation in our trial was perceived lack of effectiveness. Increased attendance of follow-up and more frequent contact with patients scheduled to undergo cytisine therapy might be requested to reduce the risk of discontinuation. 
In this study, we excluded patients treated with NRT because their smoking status could not be confirmed with the urine cotinine test. Moreover, cytisine was found to be superior to NRT therapy in a large randomized trial [12].

Although West et al. [26] verified smoking cessation by evaluating the concentrations of carbon monoxide, we assessed urine cotinine levels; it is considered to be a stronger indicator of smoking cessation over 48-72 hours [27].

The pharmacodynamics of cytisine is a matter of concern because it does not cross the blood-brain barrier. Additionally, there is no information on serious adverse events in patients with mood disorders and other addictions. Varenicline is a synthetic drug that binds to the same a4- $\beta 2$ nAChR as cytisine and crosses the blood-brain barrier with a marked effect on the receptors [28]. Furthermore, in 2009, the Food and Drug Administration released a black box warning against varenicline, associating the drug to mental health disorders [29], although further studies did not support its detrimental effect on mood disorders [30, 31]. Nevertheless, varenicline use was related to a higher risk of sleep disorders or anxiety syndromes [22]. In our study, patients treated with cytisine rarely reported increased anxiety or insomnia in both groups.

Our study has a few limitations. First, the study was not randomized and did not include a placebo control group. Second, cytisine intake was at the discretion of the patients, and this may have led to an entry of bias. Third, some patients were lost to follow-up visits, especially from the control group (29\%). However, such patients were contacted via phone, and none of them declared smoking cessation. Fourth, patients were followed up only for a short term of 30 days, nevertheless, the follow-up did include cotinine assessment as an objective biomarker. Finally, the small sample size limits our findings. Despite these limitations, our study provides important data regarding cytisine use in smoking patients with CAD. Our findings suggest that cytisine use may not be contraindicated in CAD patients including the ACS group 30 days after $\mathrm{PCI}$. To increase compliance, patients undergoing cytisine therapy should be regularly contacted and supported.

\section{CONCLUSIONS}

Cytisine is a safe and promising drug for the treatment of patients with $C A D$ initiated 30 days after $\mathrm{PCl}$. However, the compliance of the patients is low, including patients who do not start and do not complete the treatment. Owing to the low cost, cytisine therapy may be beneficial for smoking cessation in a wide group of patients with CAD. Further research is required to confirm its efficacy and safety.

\section{Article information}

Conflict of interest: $A B$ acquired consulting fees from Sanofi-Aventis, AstraZeneca, Bristol-Myers Squibb/Pfizer, GlaxoSmithKline, Bayer, and Novartis; investigator fees from Sanofi-Aventis, AstraZeneca, GlaxoSmithKline, Novartis, Bristol-Myers Squibb/Pfizer, and Eisai; and honoraria for lectures from Sanofi-Aventis, AstraZeneca, Bristol-Myers Squibb/Pfizer, and Novartis. BR received honoraria for lectures from Werfen, Boehringer-Ingelheim, and GE Healthcare.

Funding: This work was supported by the Centre of Postgraduate Medical Education, Warsaw, Poland (grant number 501-1-10-1416/17). The sponsor was not involved in study design; data collection, analysis, and interpretation; manuscript writing; or manuscript publication decision.

Open access: This article is available in open access under Creative Common Attribution-Non-Commercial-No Derivatives 4.0 International (CC BY-NC-ND 4.0) license, allowing to download articles and share them with others as long as they credit the authors and the publisher, but without permission to change them in any way or use them commercially. For commercial use, please contact the journal office at kardiologiapolska@ptkardio.pl.

How to cite: Ramotowski B, Budaj A. Is cytisine contraindicated in smoking patients with coronary artery disease after percutaneous coronary intervention? Kardiol Pol. 2021; 79(7-8): 813-819, doi: 10.33963/KP.a2021.0025.

\section{REFERENCES}

1. Erhardt L. Cigarette smoking: an undertreated risk factor for cardiovascular disease. Atherosclerosis. 2009; 205(1):23-32, doi: 10.1016/j.atherosclerosis.2009.01.007, indexed in Pubmed: 19217623.

2. Jha P. Avoidable global cancer deaths and total deaths from smoking. Nat Rev Cancer. 2009; 9(9): 655-664, doi: 10.1038/nrc2703, indexed in Pubmed: 19693096.

3. Jankowski P, Kawecka-Jaszcz K, Kopeć G, et al. Polish Forum for Prevention Guidelines on Smoking: update 2017. Kardiol Pol. 2017; 75(4): 409-411, doi: 10.5603/KP.2017.0066, indexed in Pubmed: 28421582.

4. Kozieł P, Jankowski P, Kosior DA, et al. Smoking cessation in patients with established coronary artery disease: data from the POLASPIRE survey. Kardiol Pol. 2021; 79(4): 418-425, doi: 10.33963/KP.15854, indexed in Pubmed: 33687865.

5. Piepoli MF, Hoes AW, Agewall S, et al. ESC Scientific Document Group. 2016 European Guidelines on cardiovascular disease prevention in clinical practice: The Sixth Joint Task Force of the European Society of Cardiology and Other Societies on Cardiovascular Disease Prevention in Clinical Practice (constituted by representatives of 10 societies and by invited experts) developed with the special contribution of the European Association for Cardiovascular Prevention \& Rehabilitation (EACPR). Eur Heart J. 2016; 37(29): 2315-2381, doi: 10.1093/eurheartj/ehw106, indexed in Pubmed: 27222591.

6. Stead LF, Perera R, Bullen C, et al. Nicotine replacement therapy for smoking cessation. Cochrane Database Syst Rev. 2012; 11:CD000146, doi: 10.1002/14651858.cd000146.pub3, indexed in Pubmed: 23152200.

7. Cahill K, Lindson-Hawley N, Thomas KH, et al. Nicotine receptor partial agonists for smoking cessation. Cochrane Database Syst Rev. 2016; 2016(5):CD006103, doi: 10.1002/14651858.CD006103.pub7, indexed in Pubmed: 27158893.

8. Windle SB, Dehghani P, Roy N, et al. EVITA Investigators. Smoking abstinence 1 year after acute coronary syndrome: follow-up from a randomized controlled trial of varenicline in patients admitted to hospital. CMAJ. 2018; 190(12): E347-E354, doi: 10.1503/cmaj.170377, indexed in Pubmed: 29581161.

9. Coe JW, Brooks PR, Vetelino MG, et al. Varenicline: an alpha4beta2 nicotinic receptor partial agonist for smoking cessation. J Med Chem. 2005; 48(10): 3474-3477, doi: 10.1021/jm050069n, indexed in Pubmed: 15887955.

10. Tutka P, Vinnikov D, Courtney RJ, Benowitz NL. Cytisine for nicotine addiction treatment: a review of pharmacology, therapeutics and an update of clinical trial evidence for smoking cessation. Addiction. $2019 ; 114(11)$ : 1951-1969, doi: 10.1111/add.14721, indexed in Pubmed: 31240783.

11. Courtney RJ, McRobbie $H$, Tutka $P$, et al. Effect of cytisine vs varenicline on smoking cessation: A randomized clinical trial. JAMA. 2021;326(1):56-64, doi: 10.1001/jama.2021.7621, indexed in Pubmed: 34228066 
12. Walker $\mathrm{N}$, Howe $\mathrm{C}$, Glover $\mathrm{M}$, et al. Cytisine versus nicotine for smoking cessation. N Engl J Med. 2014; 371(25): 2353-2362, doi: 10.1056/NEJMoa1407764, indexed in Pubmed: 25517706.

13. Desmoxan consumer medicine information. National Drug\&Alcohol Research Centre, Sydney, Australia. https://ndarc.med.unsw.edu.au/sites/default/files/ndarc/resources/Desmoxan.pdf (13.08.2021).

14. Barlow RB, McLeod LJ. Some studies on cytisine and its methylated derivatives. Br J Pharmacol. 1969; 35(1): 161-174, doi: 10.1111/j.14765381.1969.tb07977.x, indexed in Pubmed: 4387392.

15. Schmidt F. Medical support of nicotine withdrawal. Report on a double blind trial in over 5000 smokers [German]. MMW Munch Med Wochenschr. 1974; 116(11): 557-564, indexed in Pubmed: 4208732.

16. Zatonski W, Cedzynska $M$, Tutka $P$, et al. An uncontrolled trial of cytisine (Tabex) for smoking cessation. Tob Control. 2006; 15(6): 481-484, doi: 10.1136/tc.2006.016097, indexed in Pubmed: 17130378.

17. Yeh E, Levasseur G, Kaiserman MJ. Evaluation of urinary cotinine immunoassay test strips used to assess smoking status. Nicotine Tob Res. 2011; 13(11): 1045-1051, doi: 10.1093/ntr/ntr127, indexed in Pubmed: 21778149.

18. Kozlowski LT, Porter CQ, Orleans CT, et al. Predicting smoking cessation with self-reported measures of nicotine dependence: FTQ, FTND, and HSI. Drug Alcohol Depend. 1994; 34(3): 211-216, doi: 10.1016/03768716(94)90158-9, indexed in Pubmed: 8033758.

19. Heatherton TF, Kozlowski LT, Frecker RC, et al. The Fagerström test for nicotine dependence: a revision of the Fagerström tolerance questionnaire. Br J Addict. 1991; 86(9): 1119-1127, doi: 10.1111/j.1360-0443.1991. tb01879.x, indexed in Pubmed: 1932883.

20. Targowski T, From S, Rozyńska R, et al. Effect of some demographic and social factors on the degree of nicotine addiction and motivation to quit smoking in healthy people [article in Polish]. Pneumonol Alergol Pol. 2004; 72(5-6): 198-200, indexed in Pubmed: 15757258.

21. Mills EJ, Thorlund K, Eapen S, et al. Cardiovascular events associated with smoking cessation pharmacotherapies: a network meta-analysis. Circulation. 2014; 129(1):28-41, doi: 10.1161/CIRCULATIONAHA.113.003961, indexed in Pubmed: 24323793.

22. Rigotti NA, Pipe AL, Benowitz NL, et al. Efficacy and safety of varenicline for smoking cessation in patients with cardiovascular disease: a randomized trial. Circulation. 2010; 121(2): 221-229, doi: 10.1161/CIRCULATIONAHA.109.869008, indexed in Pubmed: 20048210.
23. Hajek $P, M c$ Robbie $H$, Myers K. Efficacy of cytisine in helping smokers quit: systematic review and meta-analysis. Thorax. 2013; 68(11): 1037-1042, doi: 10.1136/thoraxjnl-2012-203035, indexed in Pubmed: 23404838.

24. Gurbel PA, Bliden KP, Hiatt BL, et al. Clopidogrel for coronary stenting: response variability, drug resistance, and the effect of pretreatment platelet reactivity. Circulation. 2003; 107(23):2908-2913, doi: 10.1161/01. CIR.0000072771.11429.83, indexed in Pubmed: 12796140.

25. McAllister KSL, Ludman PF, Hulme W, et al. British Cardiovascular Intervention Society and the National Institute for Cardiovascular Outcomes Research. A contemporary risk model for predicting 30-day mortality following percutaneous coronary intervention in England and Wales. Int J Cardiol.2016;210: 125-132, doi: 10.1016/j.ijcard.2016.02.085, indexed in Pubmed: 26942330.

26. West R, Zatonski W, Cedzynska M, et al. Placebo-controlled trial of cytisine for smoking cessation. N Engl J Med. 2011; 365(13): 1193-1200, doi: 10.1056/NEJMoa1102035, indexed in Pubmed: 21991893.

27. Jarvis MJ, Tunstall-Pedoe $\mathrm{H}$, Feyerabend $\mathrm{C}$, et al. Comparison of tests used to distinguish smokers from nonsmokers. Am J Public Health. 1987; 77(11): 1435-1438, doi: 10.2105/ajph.77.11.1435, indexed in Pubmed: 3661797.

28. Rollema $\mathrm{H}$, Shrikhande A, Ward KM, et al. Pre-clinical properties of the alpha4beta2 nicotinic acetylcholine receptor partial agonists varenicline, cytisine and dianicline translate to clinical efficacy for nicotine dependence. Br JPharmacol. 2010; 160(2):334-345, doi: 10.1111/j.14765381.2010.00682.x, indexed in Pubmed: 20331614.

29. Food and Drug Administration (FDA). Drug Safety Information for Healthcare Professionals:Varenicline (marketed as Chantix) and Bupropion (marketed as Zyban, Wellbutrin, and generics), 2009. https://wayback.archive-it. org/7993/20170406005315/https:/www.fda.gov/Drugs/DrugSafety/DrugSafetyPodcasts/ucm170906.htm (30.03.2020).

30. Davies NM, Thomas KH. The Food and Drug Administration and varenicline: should risk communication be improved? Addiction. 2017; 112(4): 555-558, doi: 10.1111/add.13592, indexed in Pubmed: 27558015.

31. Gershon AS, Campitelli MA, Hawken S, et al. Cardiovascular and neuropsychiatric events after varenicline use for smoking cessation. Am J Respir Crit Care Med. 2018; 197(7): 913-922, doi: 10.1164/rccm.201706-1204OC, indexed in Pubmed: 29260881. 